\title{
GONADOTROPHIN EXCRETION IN OVARIECTOMIZED BITCHES
}

\author{
E. T. BELL, M. F. PARKES AND D. W. GHRISTIE \\ Endocrine Unit, Petfoods Limited, Melton Mowbray, Leicestershire
}

(Received 30th October 1970)

\begin{abstract}
Summary. Results of urinary assays of total gonadotrophic activity, FSH and LH in ovariectomized Beagle bitches are reported. Urine samples collected from animals in metabolism crates were extracted by the tannic acid precipitation technique.

Very low levels of total gonadotrophic activity were found when the mouse uterus test was employed; activity being undetectable in six out of thirteen animals. Levels of FsH could generally be measured by the mouse ovarian augmentation test. In a group of six bitches, the individual means for FSH output ranged from $<4.5$ to $21 \cdot 6$ i.u. $/ 24 \mathrm{hr}$. Levels of $\mathrm{LH}$ were assayed by the ovarian ascorbic acid depletion test in a series of ten animals and values ranged from $<5.0$ to $10 \cdot 4$ i.u. $/ 24 \mathrm{hr}$.
\end{abstract}

\section{INTRODUCTION}

There are no reports in the literature in which canine urinary gonadotrophins have been measured by techniques satisfactory for quantitative work. In the present study involving ovariectomized Beagle bitches, an attempt has been made to measure urinary total gonadotrophic activity by the mouse uterus test (Loraine \& Brown, 1959), and FSH and LH by the mouse ovarian augmentation test (Brown, 1955) and rat ovarian ascorbic acid depletion test (Parlow, 1961), respectively. The urine samples were extracted by the Johnsen (1958) tannic acid method as described for human urine.

\section{MATERIALS AND METHODS}

\section{Animals}

A total of twenty adult Beagle bitches which had been ovariectomized at least 6 months before the commencement of the study was employed. Complete 24-hr urine samples were collected while the animals were confined in metabolism crates. During this time, they continued to eat and behave normally and did not appear to be stressed. A layer of gauze was placed below the floor of the cage to ensure minimum contamination of the urine with faeces, food and hair. After collection, the urine samples were refrigerated, or deep frozen if extraction was to be delayed for more than a few days.

\section{Extraction method}

The 24-hr urine volume obtained from the animals employed in the study 
varied between 250 and $500 \mathrm{ml}$ and two or three $24-\mathrm{hr}$ samples were generally combined before extraction by the Johnsen (1958) tannic acid precipitation technique. Recovery experiments involving the addition of Pergonal (G. D. Searle \& Co.) to urine before extraction indicated that approximately $80 \%$ of the hormone could be recovered when assays were conducted by the mouse uterus test. Dilution of the urine samples with water before extraction was found to result in a decreased recovery of Pergonal and all extractions have been performed using undiluted urine.

\section{Assay methods}

The mouse uterus test was conducted according to the specifications of Loraine \& Brown (1959), except that the material to be assayed was administered in five subcutaneous injections of $0.2 \mathrm{ml}$ over a 3-day period. At autopsy approximately $65 \mathrm{hr}$ after the first injection, the uteri were freed from fat and connective tissue by the method of Christie \& Bell (1970) before being weighed on a torsion balance accurate to $0.1 \mathrm{mg}$. Assays of FSH were performed by the mouse ovarian augmentation test (Brown, 1955). Doses of 40 i.u. HCG were used to augment the FSH response and mice received five subcutaneous injections of $0.2 \mathrm{ml}$ over a 3-day period (Bell \& Christie, 1970). For both the mouse uterus and ovarian augmentation tests, animals were obtained from Messrs Schofield of Oldham. The specifications for the ovarian ascorbic acid depletion (OAAD) test were as described by Schmidt-Elmendorff \& Loraine (1962), except that the modification of Bell, Loraine, Mukerji \& Visutakul (1965) in which the unknown material is injected by the intraperitoneal route was employed. Rats of the Wistar strain, obtained from Scientific Animal Services, Ash, Canterbury, were used. The bioassays were generally of a $2+2$ design using two-, three- and fourfold dose intervals for the total gonadotrophin, FSH and LH assays, respectively. The results were calculated by an Olivetti Programma 101 using a programme based on the method described by Gaddum (1953). The mean index of precision $(\lambda)$ for the mouse uterus test was $0 \cdot 18$, the corresponding figures for the ovarian augmentation and OAAD tests were 0.26 and $0 \cdot 36$, respectively.

\section{RESULTS}

In an initial series of experiments, a total of nineteen 48- or 72-hr urine samples was collected from thirteen ovariectomized bitches and assayed by the mouse uterus test. No evidence of toxicity of the extract as judged by loss of coat condition or body weight was noted in the assay animals and there was no mortality. Very low gonadotrophin levels were found; activity was undetectable in ten samples, being $<0.01$ ampoules Second IRP-HMG/24 hr. In seven bitches, gonadotrophin levels were measurable and values ranged from 0.003 to 0.20 ampoules Second IRP-HMG/24 hr. However, the gonadotrophin levels in individual bitches were variable because, when further urine samples were obtained from two of the animals in which activity had been detected, no hormone could be measured. At the time the above studies were conducted, preliminary assays with the mouse ovarian augmentation test indicated that 
urinary FSH activity could be measured. Accordingly, urine samples were collected from ovariectomized bitches for FsH assays. The animals were placed in metabolism crates for periods of time ranging from 2 to 6 days and the urine was generally extracted and assayed as 48-hr samples. The FsH results obtained in a series of six bitches are shown in Table 1 .

Activity could usually be detected and approximately half the assays were calculated using a $2+2$ design. In the assays in which only one dose level of the unknown fell within the working range of the standard curve, the assay was calculated on a $2+1$ basis. Table 1 shows the marked degree of variability which occurred in FSH excretion, both between animals and within the same bitch. As much as a sixfold variation was noted within Bitches 147 and 149, while a fivefold variation was noted between Bitches 150 and 158. The assays conducted in each animal were not on consecutive urine samples and this may account for

TABLE 1

URINARY FSH VALUES IN OVARIECTOMIZED

BEAGLE BITCHES

\begin{tabular}{c|c|rr}
\hline Bitch no. & $\begin{array}{c}\text { No. of } \\
\text { assays }\end{array}$ & \multicolumn{2}{|c}{$\begin{array}{c}\text { FSH excretion i.u./24 } \mathrm{hr} \\
\text { Mean }\end{array}$} \\
& & & \multicolumn{1}{c}{ Range } \\
\hline 146 & 6 & 13.4 & 9.0 to 17.6 \\
147 & 6 & 5.8 & 2.0 to 11.7 \\
149 & 6 & $<10.0$ & $<2.4$ to 15.0 \\
150 & 5 & 21.6 & 13.0 to 41.3 \\
158 & 7 & $<4.5$ & $<2.4$ to 8.4 \\
159 & 5 & 11.7 & 8.0 to 17.4 \\
\hline
\end{tabular}

part of the variability. The results of FSH assays in four bitches from which urine was collected for 5 or 6 consecutive days are shown in Text-fig. 1. The variation between bitches is still marked but within individual animals it is rather less than that noted in Table 1, being approximately twofold in Bitches 148 and 151.

In view of the relative ease with which FSH could be measured in ovariectomized bitches as compared to total gonadotrophic activity, it appeared relevant to study the excretion of total gonadotrophic activity, FSH and LH in individual animals. Accordingly, urine was collected for a period of 6 days from each of ten ovariectomized bitches. The 6-day urine collection from each animal was pooled and then divided into three equal aliquots. These were extracted separately and used for assay by the mouse uterus, ovarian augmentation and OAAD tests.

The extracts were assayed in two assays by the mouse uterus and ovarian augmentation tests and in three assays by the OAAD test. All the urine extracts were assayed at two dose levels except in the mouse uterus test where, because of the low values encountered previously, some samples were assayed at only one dose level.

The results obtained are shown in Table 2. It can be seen that, with the exception of the high figure in Bitch 155, the mouse uterus test results are rather similar to those reported above. The FSH values are at the lower end of the range shown in Table 1 but activity was detectable in all but two samples. The LH assay 


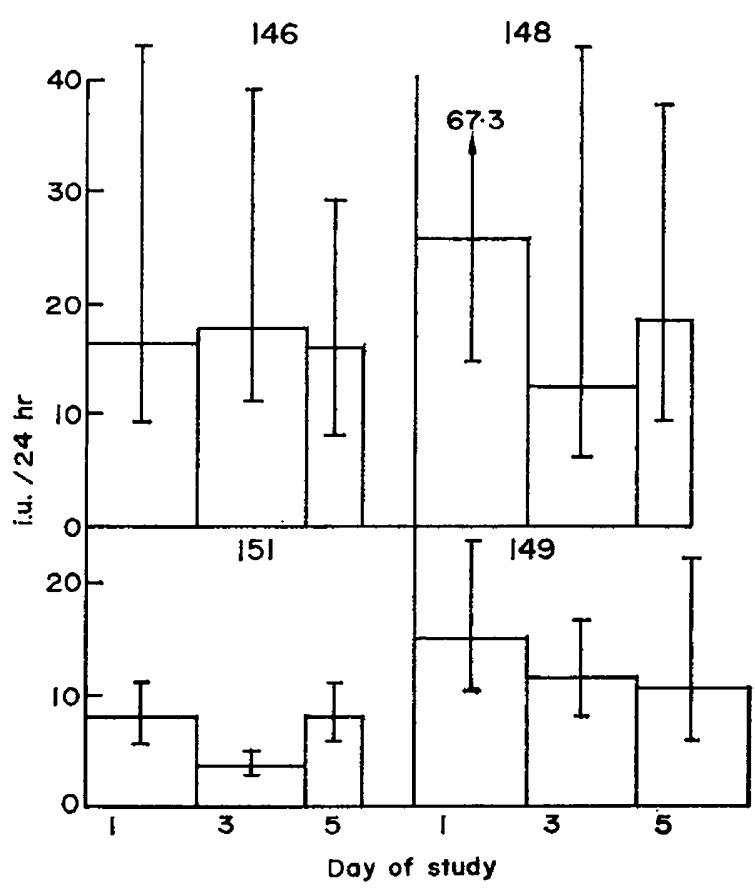

TexT-FIG. 1. Urinary FSH excretion in four ovariectomized Beagle bitches.

in Bitch 167 had a reverse slope, while activity was undetectable in two other animals. No evidence of toxicity following intraperitoneal injection of the extracts in the OAAD test was noted and there was no mortality in the test animals. The FSH/LH ratio was rather variable ranging from $<0.32$ to $>2 \cdot 28$.

TABLE 2

URINARY GONADOTROPHIN ASSAYS IN OVARIEGTOMIZED BITCHES

\begin{tabular}{|c|c|c|c|c|}
\hline Bitch no. & $\begin{array}{c}\text { Total gonadotrophin } \\
\text { ampoules } 2 \mathrm{nd} \text { IRP-HMG } \\
\qquad / 24 \mathrm{hr}\end{array}$ & $\begin{array}{c}F S H \\
(i . u . / 24 h r)\end{array}$ & $\begin{array}{c}L H \\
(\text { i.u. } / 24 h r)\end{array}$ & $F S H / L H$ \\
\hline $\begin{array}{l}146 \\
147 \\
149 \\
155 \\
156 \\
159 \\
163 \\
164 \\
165 \\
167\end{array}$ & $\begin{array}{r}0.029 \\
0.039 \\
0.025 \\
>0.063 \\
0.028 \\
<0.019 \\
0.011 \\
0.014 \\
0.013 \\
<0.019\end{array}$ & $\begin{array}{r}4 \cdot 1 \\
4.6 \\
3.4 \\
9.0 \\
<3.0 \\
<3.0 \\
10.0 \\
3.9 \\
11.4 \\
3.3\end{array}$ & $\begin{array}{r}9.8 \\
10.4 \\
8.2 \\
3.2 \\
9 \cdot 4 \\
3 \cdot 1 \\
<5.0 \\
5.7 \\
<5.0 \\
\end{array}$ & $\begin{array}{r}0.42 \\
0.44 \\
0.41 \\
2.81 \\
<0.32 \\
<0.97 \\
>2.00 \\
0.68 \\
>2.28 \\
\end{array}$ \\
\hline Mean & $<0.029$ & $<5.6$ & $<6.0$ & $1 \cdot 15$ \\
\hline
\end{tabular}

\section{DISGUSSION}

The main finding to emerge from the present study is that gonadotrophic activity can be measured in the urine of ovariectomized Beagle bitches. Such 
animals were chosen for this investigation because it was hoped that, as a result of the ovariectomy, higher gonadotrophin levels would be found than those occurring in intact females. The assays were all conducted at least 6 months after ovariectomy. It is likely, therefore, that, providing the bitch responds in the same way as other experimental animals, pituitary gonadotrophin secretion would have reached high levels before the commencement of the study. The stage of the oestrous cycle at which ovariectomy is conducted may influence the rate of increase and absolute gonadotrophin level attained but no information on this point is available from the present study. Limited evidence suggests that ovariectomy does result in raised gonadotrophin output since both FSH and total gonadotrophic activity were undetectable in urine collected from bitches during pro-oestrus and oestrus.

In the initial series of assays by the mouse uterus test, a high proportion of the urinary extracts contained no detectable gonadotrophin. It appeared possible that destruction of the gonadotrophins had occurred and experiments were therefore conducted to investigate this point. The metabolism crates were made of galvanized metal and since heavy metals may cause slight inactivation of gonadotrophins in vitro (Butt, Crooke, Cunningham \& Evans, 1961), the zinc content of canine urine was measured. Urine samples collected in metabolism crates and in stainless steel bowls were compared and both found to have a zinc content of $4 \mathrm{ppm}$. Furthermore, since similar recoveries of Pergonal were obtained when urine was collected in metal or plastic covered cages and assayed by the mouse uterus test, it is unlikely that metal contamination of the urine has any effect on gonadotrophin levels.

Visutakul, Bell, Loraine \& Fisher (1966a, b) demonstrated that incubation in vitro with urea could reduce the biological activity of pituitary and urinary FSH and LH. Urinary urea levels in dogs on very high protein diets may sometimes be elevated, though urea determinations on urine obtained from ovariectomized animals gave values below the level at which inactivation of gonadotrophins in vitro had been demonstrated.

The decrease in the uterine weight of immature mice treated with HCG is used as an assay method for the gonadotrophin-inhibiting factor (see Krishnamurti \& Bell, 1967). If this inhibitor were present in canine urine, it might antagonize the effects of FSH and LH on the mouse uterus thus resulting in an underestimate of activity. No gonadotrophin-inhibiting factor could be detected when urine extracts which had been boiled to destroy the gonadotrophins were assayed in HCG-treated mice.

None of the experiments described above provides any indication that the low gonadotrophin levels measured by the mouse uterus test result from hormone inactivation. It must, therefore, be assumed that the results obtained represent a true estimate of canine urinary gonadotrophin. An alternative to urine collections in metabolism crates would be the use of an indwelling catheter. This approach would probably require the dog to be restrained and is not feasible for urine collection over a number of days. For these reasons, no urine samples have been collected using such a catheter. The use of a catheter to collect urine ensures that the bladder is empty at the beginning and end of each 24-hr period. Bitches in metabolism crates do not necessarily have empty bladders at 
the start of each 24-hr period and this may contribute to the day to day fluctuations in gonadotrophin levels when the results are expressed on a 24-hr basis.

Relatively little information is available on urinary gonadotrophins measured by bioassay following ovariectomy in other mammals but data are available on the excretion of total gonadotrophic activity, FSH and LH in intact postmenopausal women. Table 3 shows a comparison of the results in Table 2 with mean

TABLE 3

URINARY GONADOTROPHIN EXCRETION

\begin{tabular}{|c|c|c|c|c|}
\hline Subject & $\begin{array}{c}\text { Total gonadotrophin } \\
\text { ampoules } 2 n d \text { IRP-HMG } \\
\text { |24 hr }\end{array}$ & $\begin{array}{c}\text { FSH } \\
(\text { i.u. } / 24 h r)\end{array}$ & $\underset{(i . u . / 24 h r)}{L H}$ & FSH $/ L H$ \\
\hline $\begin{array}{l}\text { Ovariectomized } \\
\text { bitches }(12.5 \mathrm{~kg}) \\
\text { Results } \times 5\end{array}$ & $<0.15$ & $<28 \cdot 0$ & $<30 \cdot 0$ & 0.93 \\
\hline $\begin{array}{l}\text { Postmenopausal women } \\
(60 \text { to } 65 \mathrm{~kg})\end{array}$ & $1 \cdot 0$ & 30 & 100 & $0 \cdot 3$ \\
\hline Ratio $(\%)$ & $<15$ & $<93$ & $<30$ & \\
\hline
\end{tabular}

values in postmenopausal women derived from the literature. The mean body weight of the ten bitches was $12.5 \mathrm{~kg}$ and in order to facilitate the comparison, the canine results have been multiplied by 5 so that the body weights of the two groups are comparable. Table 3 shows that the bitch excretes some $93 \%$ of the FsH produced by postmenopausal women but only about $30 \%$ of the LH. The disparity in the mouse uterus test results is much greater, the mean figure in the bitch being less than one-sixth of that in the human. Two explanations can be advanced to account for the differing FSH and LH excretion values. First, that the bitch excretes relatively less LH than do postmenopausal women on a weight for weight basis, and second, that the biological properties of canine and human gonadotrophins are dissimilar. It might be expected that a difference in biological characteristics would be demonstrated in the test for parallelism employed in the calculation of the bioassay results. None of the assays by the OAAD test which could be calculated on a $2+2$ basis deviated significantly from parallelism when compared with the Second IRP-HMG. In the ovarian augmentation test, approximately $15 \%$ of the assays were invalid because of lack of parallelism, generally due to absence of slope in the unknown sample. The large difference in assay results between the bitch and human obtained in the mouse uterus test is difficult to explain. The lack of specificity of this assay method and the marked effect of alterations in $\mathrm{FSH} / \mathrm{LH}$ ratio on uterine weight (Brown \& Billewicz, 1962; Lunenfeld, 1967) are well established and these factors make it difficult to draw conclusions about the results obtained.

\section{REFERENCES}

BeLl, E. T. \& Christie, D. W. (1970) Strain variation in the assay of follicle-stimulating hormone by the ovarian augmentation test in mice. Acta endocr., Copenh. 63, 275 .

Bell, E. T., Loraine, J. A., MukerjI, S. \& Visutakul, P. (1965) Further observations on the ovarian ascorbic acid depletion test for luteinizing hormone. F. Endocr. 32, 1. 
BRown, P. S. (1955) The assay of gonadotrophin from urine of non-pregnant human subjects. F. Endocr. 13, 59 .

BRown, P.S. \& Billewicz, W. Z. (1962) The response of immature mice to mixtures of gonadotrophins. F. Endocr. 24, 65.

Butt, W. R., Grooke, A. C., Cunningham, F. J. \& Evans, A. J. (1961) Ghemical reactions which affect the biological activity of human gonadotrophins. Biochem. $7.79,64$.

Christie, D. W. \& Beld, E. T. (1970) A rapid technique for the removal and cleaning of the mouse uterus in preparation for weighing. 7. Inst. Anim. Techns, 21, 58.

Gaddum, J. H. (1953) Bioassays and mathematics. Pharmac. Rev. 5, 87.

JoHnsen, S. G. (1958) A clinical routine-method for the quantitative determination of gonadotrophins in 24-hour urine samples. Acta endocr., Copenh. 28, 69.

KRIShNamurTi, M. \& BeLL, E. T. (1967) Studies on the specificity of the assay method for the gonadotrophin inhibiting factor. 7. Reprod. Fert. 13, 149.

LoRAINE, J. A. \& BROWN, J. B. (1959) A method for the quantitative determination of gonadotrophins in the urine of non-pregnant subjects. F. Endocr. 18, 77.

LunENFELd, B. (1967) In: Recent Research on Gonadotrophic Hormones, p. 48. Eds. E. T. Bell and J. A. Loraine. Livingstone, Edinburgh.

PARLow, A. F. (1961) Bioassay of pituitary luteinizing hormone by depletion of ovarian ascorbic acid. In: Human Pituitary Gonadotropins, p. 300. Ed. A. Albert. Thomas, Springfield.

Schmidt-Elmendorff, H. \& Loraine, J. A. (1962) Some observations on the ovarian ascorbic acid depletion method as a test for luteinizing hormone activity. F. Endocr. 23, 413.

Visutakul, P., Bell, E. T., Loraine, J. A. \& Fisher, R. B. (1966a) The effect of urea on the biological activity of pituitary gonadotrophins. F. Endocr. 36, 15 .

Visutakul, P., Bell, E. T., Loraine, J. A. \& Fisher, R. B. (1966b) The effect of urea on the biological activity of gonadotrophins of placental endometrial and urinary origin. J. Endocr. 36, 23. 